\title{
Review of The economics of ecosystems and biodiversity: ecological and economic foundations, edited by Pushpam Kumar. London: Earthscan, 2010, 400pp.
}

\section{JOHN LIVERNOIS \\ University of Guelph}

This book provides an encyclopedic review and synthesis of the literature on the economics of ecosystems and biodiversity. It is a must-have reference book for anyone doing valuation studies of environmental resources and for instructors and scholars in this area. In addition to what one would expect of any exhaustive review of the economic valuation literature, it provides appendices containing compilations of more than a thousand monetary values gleaned from the literature (more on this below), and a number of chapters linking biodiversity, ecosystems, and ecosystem services to one another, to socio-cultural contexts, to measurement, and to economics.

The book has its roots in a declaration by the environment ministers of the G8 plus five major newly industrializing countries in a meeting that took place in 2007. The ministers called for a study that would evaluate the "global economic benefit of biological diversity, the costs of the loss of biodiversity and the failure to take protective measures versus the costs of effective conservation". The result was a major research undertaking involving a huge international team that is hosted by the United Nations Environment Program and receives financial support from the European Commission and a number of countries. This book is one part of the culmination of that undertaking. It provides the technical and scientific basis for four companion works: a book containing recommendations for national policy-makers, another for local and regional policy-makers, another for business leaders, and an internet resource for citizens (www.teebweb.org).

There are seven chapters in the book, each written by a different team of researchers; in addition, there are three appendices also written by different teams of researchers. Finally, there is a preface written

\footnotetext{
${ }^{1}$ See: http://www.teebweb.org/AboutTEEB/Background/HistoryofTEEB/tabid/1247/Default.aspx
} 
by the study leader Pavan Sukhdev, and an introduction written by Pushpam Kumar, the book's editor. Despite the large number of authors (12 coordinating lead authors, 20 lead authors, and more than 50 contributing authors) the book is cohesive, organized, and flowing. This must not have been an easy task.

Chapter 1 discusses the challenges of integrating the disciplines of economics and ecology. As the introductory chapter, it also presents the framework and backbone for thinking about the linkages between ecosystems and the economy to be used throughout the book. Chapter 2 discusses the current understanding of the relationships between biodiversity, the structure and functioning of ecosystems, and the provision of ecosystem services. Chapter 3 explores the strengths and weaknesses of available measures and indicators of biodiversity and ecosystem status and concludes that most of the available indicators are not useful for economic valuation studies per se. Chapter 4 discusses concepts of valuation including economic valuation. Chapter 5 provides a review of the literature on economic valuation methods. Chapter 6 discusses the issues surrounding the choice of discount rate to use in valuation. Finally, Chapter 7 summarizes and synthesizes the previous six chapters.

I will declare at the outset that I am a mainstream environmental economist. Therefore, the heart and soul of the book for me are in Chapters 5 and 6, "The economics of valuing ecosystem services and biodiversity" and "Discounting, ethics and options for maintaining biodiversity and ecosystem integrity", respectively. These chapters present excellent summaries of the state of the art and provide a thorough and concise review and synthesis of the literature. The authors cover the usual topics such as valuation methods (direct, revealed, and stated preference approaches), benefits transfer and scaling-up issues, the Ramsey discounting approach of growth theory, and implications for discounting of uncertainty and time frame. At the same time, the authors do not shy away from tackling the most troubling issues and obstacles in valuation such as preference uncertainty, the problem of valuing ecosystem resilience, dealing with option value and valuation in developing economies. There are not answers to all problems, but it is important that the limitations of valuation are clearly laid out and understood by practitioners and stakeholders.

In economics, value is an anthropocentric concept. Thus, ecosystems and biodiversity have value because of their worth to humans. And this 
makes it possible to operationalize valuation studies: one can estimate the value of an ecosystem service, for example, by looking to the value humans place on it, revealed either through behaviour in marketrelated activities or through questionnaire/stated-preference studies. Economists are quick to point out that this is the methodological starting point for valuation studies. This book does this too, but goes well beyond merely stating the assumption. For example, the Chapter 5 authors state that "[t]his valuation approach [...] should be used to complement, but not to substitute for, other legitimate ethical or scientific reasoning and arguments relating to biodiversity conservation" (p. 187). And Chapter 4 provides an illuminating review of alternative approaches to the origins and concept of value. One of its key messages is that one's concept of the value of nature "functions as a system of cultural projection which imposes a way of thinking and a form of relationship with the environment, a particular notion of property and ownership" (p. 152). As well, it "can serve as a tool for self-reflection which helps people rethink their relations to the natural environmental and increased knowledge about the consequences of consumption choices and behaviour for distant places and people" (p. 152). The chapter points out that the anthropocentric approach really views nature and human beings as being distinct from each other and reveals a "[...] neglect of intrinsic values in economics-values of nature simply for the sake of its existence, independent of any current or future usefulness to humans" (p. 161). The authors say that the question of whether or not nature has or should have intrinsic value is related to the way in which we perceive human-nature relationships.

The authors distinguish two alternative approaches to eliciting values for nature; the first is the stated preference or contingent valuation approach. Implicitly, this approach assumes that people have pre-existing and known values for nature that just need to be drawn out. Moreover, the value of nature is then the aggregation of individual values. On the other hand, what they call the "deliberative or social process" approach, in which values emerge from a communicative social process, implicitly assumes that individuals do not have pre-existing and known values for nature; nonetheless, these values evolve during the process of social deliberation. In this approach, value is not the aggregation of individual values but is a group-determined value. This approach, however, has been criticized for being open to influence by power relations in social settings. 
Though the book justifiably calls attention to the potential negative implications of the economic approach to valuation, it concludes that it clearly has considerable appeal as a decision-making and awareness mechanism. The authors concede that it is quite possible that "in the long run this approach actually will lead to the internalization of the environment into western thinking and economics" (p. 164). In addition, there are a number of practical reasons to view valuation as socially useful. As Pavan Sukhdev points out in the preface, valuation can (1) serve as a tool for self-reflection, (2) it makes explicit what would otherwise be implicit valuations made by policy-makers, and (3) demonstrates the value that nature delivers to society in a unit of account everyone understands and therefore is an important vehicle for achieving policy changes that properly take into account the importance of nature.

Pavan Sukhdev summarizes succinctly the philosophical approach to valuation adhered to throughout the book:

[W] should acknowledge the weaknesses of valuation methodology [...] (due to insufficient understanding of ecosystem dynamics and of biodiversity's role in ecosystem resilience, valuing single benefits one at a time rather than an ecosystem as a whole, not accounting for the effects of climate change on the nature and extent of ecosystem services and so on) but we should not shy away from stating best available estimates of value using the most appropriate of reviewed methodologies, strictly to help decision makers to make better informed choices. This is because the alternative is in fact ethically worse: to permit the continued absence of prices to seep even further into human consciousness and behaviour as a 'zero' price, and thus no value (p. xxiii).

Some might take exception to this view and argue that putting a wrong price on nature (which is a real possibility given all the hindrances to valuation listed above) is not likely to lead decision makers to make better choices. On the contrary, it could lead to bad choices. While there is some merit in this viewpoint, I would tend to agree with Sukhdev. Refusing to be explicit and therefore accountable about valuation means we are leaving it to others who make decisions about resource allocation that will affect the natural environment to impose their own preferences and values on the decision-making process.

As I mentioned earlier, one of the Appendices contains a valuable summary of a data base created as part of the study of the monetary 
values found in the literature for 11 main biomes/ecosystem-complexes (open-ocean, coral reefs, coastal systems, coastal wetlands, inland wetlands, rivers and lakes, tropical forests, temperate and boreal forests, woodlands, grasslands and polar and high mountain systems). The Appendix refers the reader to www.teebweb.org for the complete database, but at the time of writing, I was unable to find it. Nevertheless, the Appendix provides a comprehensive summary of monetary values screened from hundreds of publications. Combine this with the information in Appendix 2 which provides references to the published papers carefully categorized by the type of ecosystem service and valuation technique and you have an impressive and valuable collection of information.

The efforts taken in this volume and, indeed in the entire project, to bring together all that we know about the value of biodiversity and ecosystems to economies are to be highly commended. The information is up-to-date, state of the art, balanced, and exhaustive. This book is also big, both qualitatively and quantitatively. It presents an overwhelming amount of information about biodiversity and ecosystem values. Yet it also shows us how little we really know yet, and how much more work needs to be done.

John Livernois is professor and chair of economics at the University of Guelph. He received a BA (with honours) from the University of Toronto (1976), and MA (1978) and PhD (1984) from the University of British Columbia. His research interests are in the economics of natural resources and the environment with a focus on issues related to taxation, regulation, and enforcement. He has published scholarly papers in many international journals, has served on the editorial boards of the journals for both the American Association of Resource and Environmental Economists (AERE) and the Canadian Economics Association (CEA/ACE), and co-authored the textbook Mathematics for economics (MIT Press, 2001).

Contact e-mail: <live@uoguelph.ca> 